\title{
An Improved Open-Top Chamber with Solar-Heated Double Funnels That Can Adapt to All Wind Directions for Simulating Future Global Warming Conditions in Rice Paddy Fields
}

\author{
Tomio Terao ${ }^{*}$, Masahiro Chiba ${ }^{2}$ \\ ${ }^{1}$ Hokuriku Research Station, Central Region Agricultural Research Center, National Agriculture and Food Research Organization, Joetsu, \\ Japan \\ ${ }^{2}$ Western Region Agricultural Research Center, National Agriculture and Food Research Organization, Fukuyama, Japan \\ Email: ^terao@affrc.go.jp, gadai@affrc.go.jp
}

How to cite this paper: Terao, T. and Chiba, M. (2016) An Improved Open-Top Chamber with Solar-Heated Double Funnels That Can Adapt to All Wind Directions for Simulating Future Global Warming Conditions in Rice Paddy Fields. Agricultural Sciences, 7, 716-731.

http://dx.doi.org/10.4236/as.2016.710067

Received: September 14, 2016

Accepted: October 24, 2016

Published: October 27, 2016

Copyright $\odot 2016$ by authors and Scientific Research Publishing Inc. This work is licensed under the Creative Commons Attribution International License (CC BY 4.0).

http://creativecommons.org/licenses/by/4.0/

\begin{abstract}
An Open-Top Chamber with Solar-heated Double Funnels (OTC-SDF2) that uses solar energy as a heating source was developed in this study. Two air entry/exit funnels were connected to the OTC via flat tunnels through which air was warmed by solar radiation. The new apparatus increased the air temperature by approximately $1^{\circ} \mathrm{C}$ throughout the chamber when more than half the energy of full sunlight was supplied. Although air flow occurs in only two directions, a nearly constant temperature increase was observed for each wind direction. This increase in temperature was stable for $1 \mathrm{~m}^{-s}$ to $4 \mathrm{~m}^{-s}$ wind speeds in every direction. This degree of warming may be adequate for screening high-temperature tolerant plants from medium to weak cultivars. The OTC-SDF2 has the potential to provide moderately high-temperature treatments for screening various cultivars/strains and may be used to evaluate easy, low-cost cropping methods associated with high-temperature stresses.
\end{abstract}

\section{Keywords}

Global Warming, High-Temperature Ripening, Grain Quality, Screening Method, Rice (Oryza sativa L.)

\section{Introduction}

Atmospheric $\mathrm{CO}_{2}$ concentrations have increased since the industrial revolution and have caused the global average surface temperature to increase, which poses future risks 
to the global climate [1]. One of the apparent agricultural effects is related to crop production, particularly grain quality deterioration in rice [2]. High temperatures during the ripening stage increase the amount of chalky grains and reduce the grain quality [3]. Genetic screening has been used to identify significant genetic factors that have been reproduced to establish new cultivars that are tolerant to high temperatures at the ripening stage [4] [5]. Other methods can also counteract high-temperature ripening, such as deep flood irrigation [6] and planting period shifts to avoid high-temperature seasons [7]. Both of these methods require effective, low cost equipment.

Several methods have been proposed or adopted to screen for high-temperature tolerant cultivars [8]-[12]. However, certain methods, such as temperature gradient chambers [8], warm water circulation [9], infrared heater arrays [10], artificial light growth chambers and phytotrons, possess significant construction and/or operational costs. Two additional methods [11] [12] were discussed in Chiba and Terao [13], who noted the disadvantages of these methods and the reliance of these methods on solar radiation, which possessed a low operational cost. Thus, solar radiation-dependent warming systems may provide a solution for low-cost treatments. In addition, the necessary equipment may be profitable because it can be used to examine numerous cultivars/strains and conduct various field trials.

Open-Top Chambers (OTCs) simulate the future environment under field conditions [14] [15]. Although OTCs were first used to simulate future atmospheric conditions, previous work has shown that when the $\mathrm{CO}_{2}$ concentration inside an OTC is increased, the temperature increase inside the OTC is large due to the lack of warm air escaping from the top. Hence, the temperature increase is another variable that must be considered if a cooling apparatus is not used [16].

Here, we propose a new type of OTC in which sun-warmed air flow enters and warms the OTC. The first type of OTC was attached to a solar-heated air-introduction tunnel (SAT), which used solar radiation to warm the passing air and increase the temperature inside the OTC [13]. In this OTC configuration, the temperature gradient is higher close to the SAT but lower close to the exit; however, enlarging the exit side opening in the exhaust tunnel largely improved the uniformity of temperature inside the OTC. Thus, the OTC-SAT configuration performed well in regions with stable wind conditions because this equipment was designed for one consistent wind direction [13].

However, OTC-SATs may not perform well in regions with unstable wind directions. In fact, they perform poorly in Fukuyama, Japan, where the wind conditions are weak and erratic [17]. Therefore, we propose an OTC-SDF, which includes two funnelshaped air intakes/exhausts on opposite sides of the OTC that can adapt to weak and erratic wind conditions and perform well in Fukuyama [17]. Although this system performed well in weak and unstable wind conditions, the temperature close to the SDF was lower than at the center of the OTC-SDF in relatively strong and stable wind conditions (the nomenclature of the chamber was OTC-SAT-E) [13]. We believe that this poor performance occurred near the SDF joint because of over-ventilation. Thus, forcing the air flow between the funnel and the OTC may improve the performance. 
We further improved the OTC-SDF by altering the SDF shape to develop the OTCSDF2 (Open-Top Chamber with Solar-heated Double Funnels 2). Moreover, the effects of increasing temperatures were evaluated under various wind conditions.

\section{Materials and Methods}

\subsection{Improved SDF Design}

The evolutionary process of the air flow-type OTC is shown in Figure 1. The OTC-SAT and OTC-SAT prototypes were designed for only one wind direction. Thus, the OTCSDF utilized two opposing wind directions by attaching funnel-shaped tunnels to opposite sides of the OTC. However, this funnel-shaped air intake reduced the efficiency of the temperature increase inside the OTC, particularly in the area close to the SDF joint, which caused an air flow disturbance [13]. However, the OTC-SDF performed well in unstable low-velocity wind conditions [17]. Therefore, we improved the SDF shape by adding a flat portion between the funnel and the OTC to suppress the air disturbance (OTC-SDF2). The OTC-SDF2 dimensions are as follows: the OTC-SDF2 width is $6 \mathrm{~m}$, the OTC length is $4 \mathrm{~m}$, the OTC height is $1.8 \mathrm{~m}$, the SDF2 length is $2 \mathrm{~m}$ and the SDF2 flat portion length is approximately $80 \mathrm{~cm}$. No black film sheets were added to the inner SDF2 surface as used in OTC-SAT [13] and OTC-SDF [17] to increase the warming efficiency in SAT or SDF.

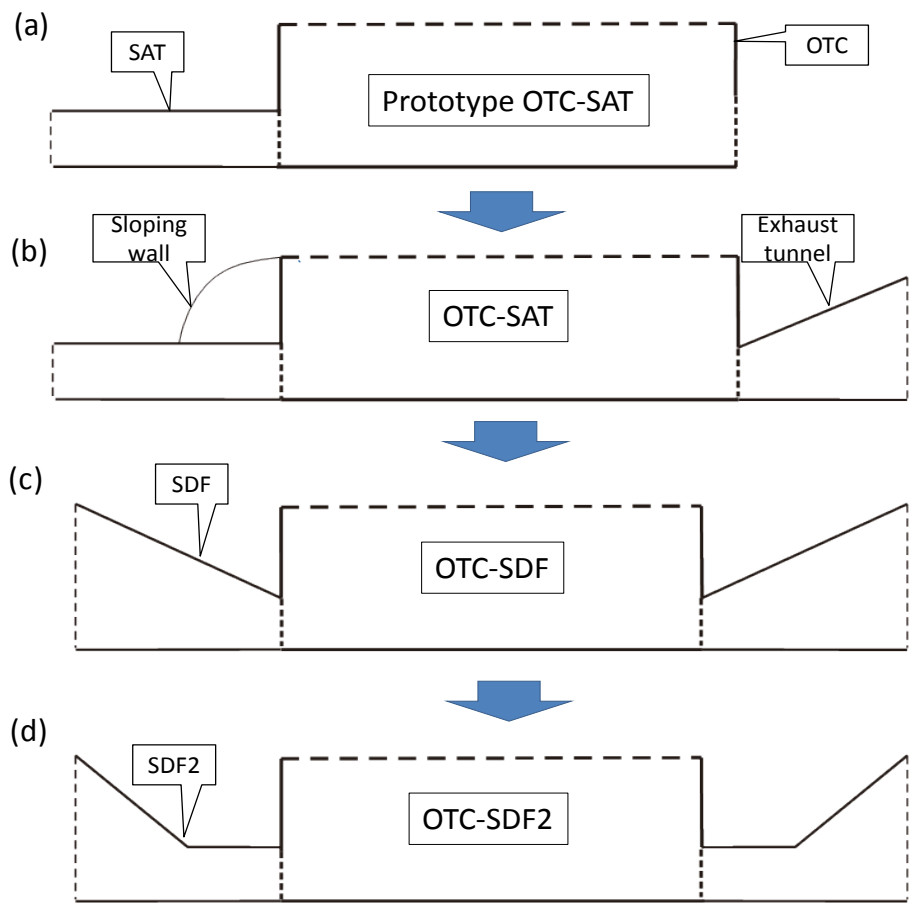

Figure 1. Evolution of types of air flow open-top chambers (OTCs) from a single wind-direction OTC with a solar-heated air-introduction tunnel (OTC-SAT) to an OTC with solar-heated double funnels (OTC-SDF2) to the proposed OTC-SDF2, which improved the SDF shape. Dashed lines represent the openings. 


\subsection{TC-SDF2 Placement in the Field}

The OTC-SDF2 devices were placed in the Hokuriku Research Station paddy field $\left(37^{\circ} 7^{\prime} \mathrm{N}, 138^{\circ} 16^{\prime} \mathrm{E}\right)$ at the Central Region Agricultural Research Center, National Agricultural and Food Research Organization, 1-2-1, Inada, Joetsu, Niigata, 943-0193, Japan in 2013. The OTC-SDF2s were placed square to the field (Scenario 1), at +30 degrees to the field (Scenario 2) and at -30 degrees (Scenario 3) to the field (Figure 2). The meteorological data, including solar radiation, wind direction and wind strength, were measured at the Hokuriku Research Station [18]. The daytime wind typically blows from the north. Therefore, the deflection angle variations from the north were generally the same as the deflection angle from the wind direction. Thus, the OTC-SDF2s were set 20 degrees west of north (Scenario 1), 50 degrees west of north (Scenario 2) and 10 degrees east of north (Scenario 3).

These three scenarios were considered as different treatments when measuring individual temperature point variations as a function of solar radiation and wind. However, the scenarios were treated as replications when analyzing the total effects of increasing temperature inside the OTC and the resulting effects on grain quality. A statistical analysis of the total effects was conducted through an analysis of variance with WallerDuncan multiple comparison test using the GLM procedure in SAS ver. 9.4 (SAS Insti-

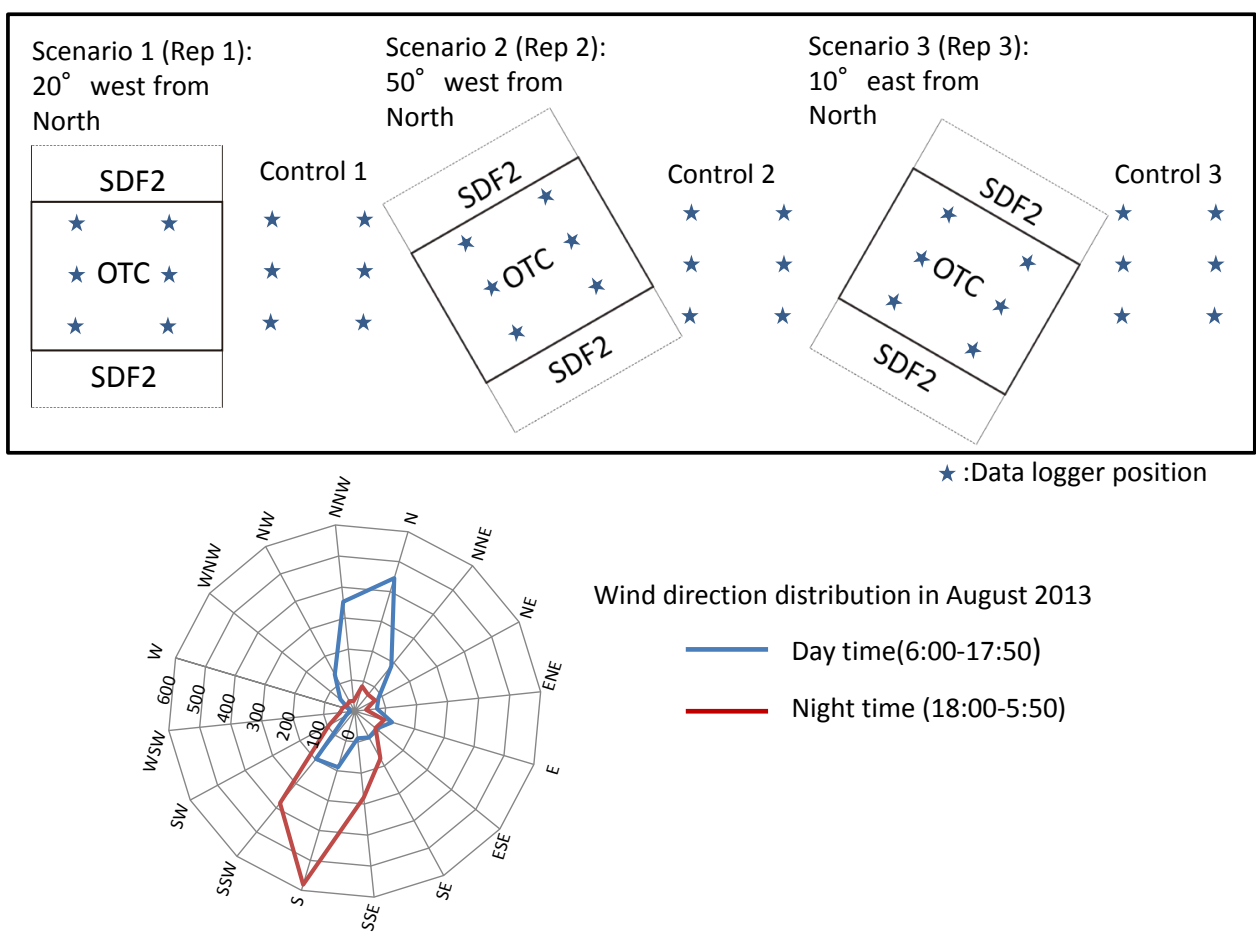

Figure 2. Placement of open-top chambers with solar-heated double funnels (OTC-SDF2) in the field (top), and the wind direction distribution chart shown in the same placement direction (bottom). The OTC-SDF2 devices were placed square to the field, at +30 degrees to the field and at -30 degrees to the field. This placement resulted in directions of 20 degrees west, 50 degrees west and 10 degrees east of the northern prevailing winds. These 3 scenarios were treated as replicates for the statistical analyses. 
tute Inc., Cary, NC, USA) and performed at the Agriculture, Forestry and Fisheries Research Information Technology Center, Ministry of Agriculture, Forestry and Fisheries, Japan.

The OTC-SDF2s were covered with plastic film $(0.1 \mathrm{~mm}$ thick, Nobi-ace-mirai, Mitsubishi Plastics Agri Dream Co., Ltd., Tokyo, Japan) on July 18, which was approximately one week before the earliest cultivar headed.

\subsection{Plant Cultivation and Temperature Measurements}

Koshihikari rice plants, the leading cultivar in Japan due to its favorable taste and texture, and ten standard cultivars with different high-temperature tolerances during the ripening stage [9] were grown in the OTC as well as in control (ambient environments). The cultivars included Fusaotome as the tolerant cultivar; Tentakaku, Hanahikari and Koshijiwase as the moderately tolerant cultivars; Hitomebore and Haenuki as the medium cultivars; Ajikodama and Kagahikari as the moderately weak cultivars; and Koshinohana and Todorokiwase as the weak cultivars. Koshihikari plants are moderately tolerant, although the Koshihikari heading date is slightly later and may avoid the hottest ripening season [9]. The seeds were sown on April 22 and transplanted on May 21 at a planting density of 22.2 hills $\cdot \mathrm{m}^{-2}$ and 3 plants per hill. Raw plants inside the OTC were tilted to allow wind to pass from one side of the SDF2 to the other. Control plots were placed next to the OTCs and planted based on the same cultivars although without an enclosure or tilting. The insides of the OTCs were separated into 3 blocks, including a northern side, center and southern side. The plants were transplanted in each block based on various orders, thereby eliminate planting order effects. The soil conditions of this field are heavy clay. Fertilizer, consisting of $3.0 \mathrm{~g} \cdot \mathrm{m}^{-2}(3.0 \mathrm{~kg} / 10 \mathrm{a})$ of each of $\mathrm{N}, \mathrm{P}_{2} \mathrm{O}_{5}$, and $\mathrm{K}_{2} \mathrm{O}$ with $1 \mathrm{~kg} \cdot \mathrm{m}^{-2}(1 \mathrm{t} / 10 \mathrm{a})$ manure, was added as a basal dose, and no top dressing was applied. The herbicides Yuniherb, comprising benzofenap + pretilachlor, and Gouwan, consisting of oxaziclomefone + clomeprop + bromobutide + bensulfuronmethyl (both from HOKKO CHEMICAL INDUSTRY CO., LTD., Tokyo, Japan), were applied 1 week before and 13 days after transplanting, respectively. The insecticide Starkle (HOKKO CHEMICAL INDUSTRY CO., LTD.), which includes dinotefuran, was applied on August 2 to protect against rice leaf bug, which generates black spots on grains. Flood irrigation followed by midseason drainage was conducted according to conventional manipulation.

Temperature was measured at 6 points inside the OTCs and in control plots using a temperature data logger (Thermochron SL type, KN Laboratories, Inc., Osaka, Japan) that was attached to the radiation shield housing, which consisted of 5 white melamine resin dish layers (18 cm diameter). The temperature was measured every $20 \mathrm{~min}$. Meteorological data, such as solar radiation and wind speed in the field of Hokuriku Research Station [18], were provided by the Crop Management under Climate Change research project.

After the plants were harvested, the brown rice quality was investigated using an ES-1000 rice inspector (Shizuoka Seiki Co., Ltd., Shizuoka, Japan). This instrument 
analyzes upper, lower and transparent images and distinguishes the regular and several types of down-grading grains according to criteria authorized by Foundation of Zenkoku Mizuho Shokuryou Kensa Kyoukai (http://www.msk.or.jp/), which supplies the standard of grain quality for various grain crops in Japan. The total number of milky white, white-belly/back, basal white and dead grains represented the total number of white immature (TWI) grains.

\section{Results}

\subsection{Evolutionary Design of the OTC-SAT and OTC-SDF}

The OTC design changes are shown in Figure 1. The prototype OTC-SAT included an air intake tunnel, through which solar radiation warms the air flowing into the OTC (Figure 1(a)). The tunnel increased the air temperature close to the tunnel, although the warming effect was not evident at the exhaust end [13]. The air flow inside the OTC was improved by adding sloping walls, and the exhaust tunnel improved the uniformity of the temperature gradient (Figure 1(b)) [13]. This design can only be utilized in regions with one stable wind direction. Thus, we created the OTC-SDF, which includes two funnel-shaped air intakes/exhausts on opposite sides of the OTC. This design performed well in areas with slow, unstable wind patterns [17]. However, relatively high wind speeds caused significantly higher temperature increases at the center of the OTC compared with the temperature increases at the intake and exhaust tunnels [13]. This temperature gradient may have occurred because of an overly large air exchange or other disturbances. Therefore, we reduced the air disturbances by placing a horizontal tunnel between the OTC and both funnels (OTC-SDF2, Figure 1(d)). This horizontal tunnel reduced the air disturbance by improving the air flow to the tunnel.

We placed the OTC-SDF2 in 3 different directions to mimic the various wind conditions in the Joetsu area of Niigata, Japan (Figure 2 upper). Figure 2 (bottom) shows the daytime and nighttime wind direction distributions from August 2013 as measured by the Hokuriku Research Station [15]. Northern winds were dominant during the daytime, whereas southern winds were dominant during the nighttime. The OTC-SDF2 was placed in different directions to analyze the various wind directions in the Joetsu region. The real wind direction settings were 20 degrees west of north in Scenario 1, 50 degrees west of north in Scenario 2 and 10 degrees east of north in Scenario 3. The actual settings are shown in Figure 3. The flat portion of the tunnel was approximately 80 cm long.

\subsection{Effects of Increases in Temperature on the OTC-SDF2}

Figure 4 shows the average daytime (06:00 - 17:40) and nighttime (18:00 - 05:40) temperatures for the different scenarios. The temperature results from the three scenarios were averaged from 4-23 August. This period included six rainy days with a precipitation amount higher than $1 \mathrm{~mm}, 10$ days with more than $8 \mathrm{~h}$ of sunshine, four days with 4 to $8 \mathrm{~h}$ of sunshine, and five days with less than $4 \mathrm{~h}$ of sunshine (the average daily sunshine duration was $7.06 \mathrm{~h}$ ). During this period, the average daily mean temperature 


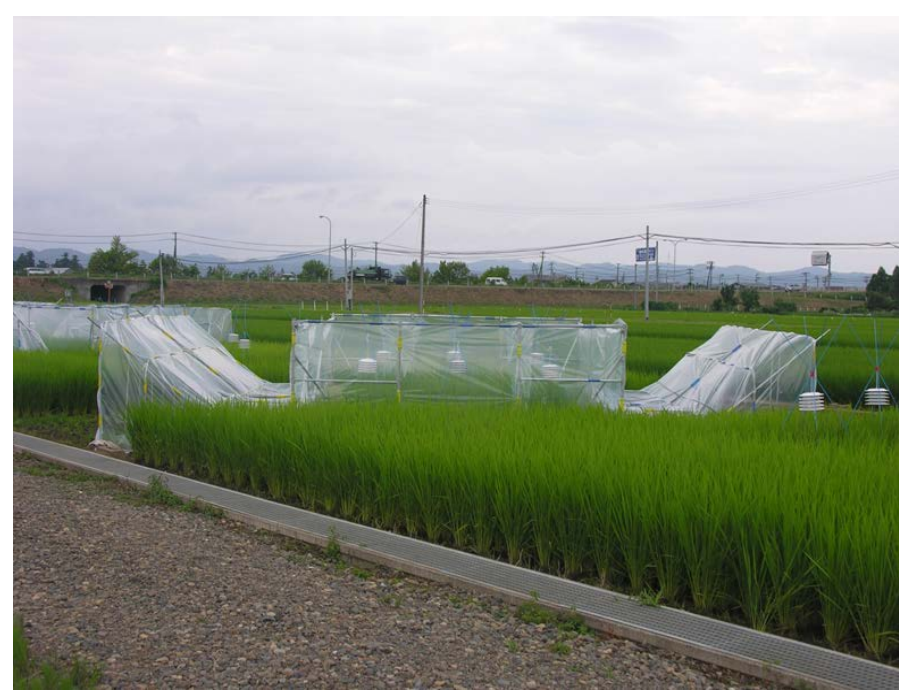

Figure 3. Example of the OTC-SDF2 field settings. Scenario 3 is shown, in which the apparatus was set approximately 30 degrees from the perpendicular direction. Thus, the right funnel is facing 10 degrees east of north. The temperature sensors inside and outside the OTC-SDF2 were covered with 5 radiation shield layers.

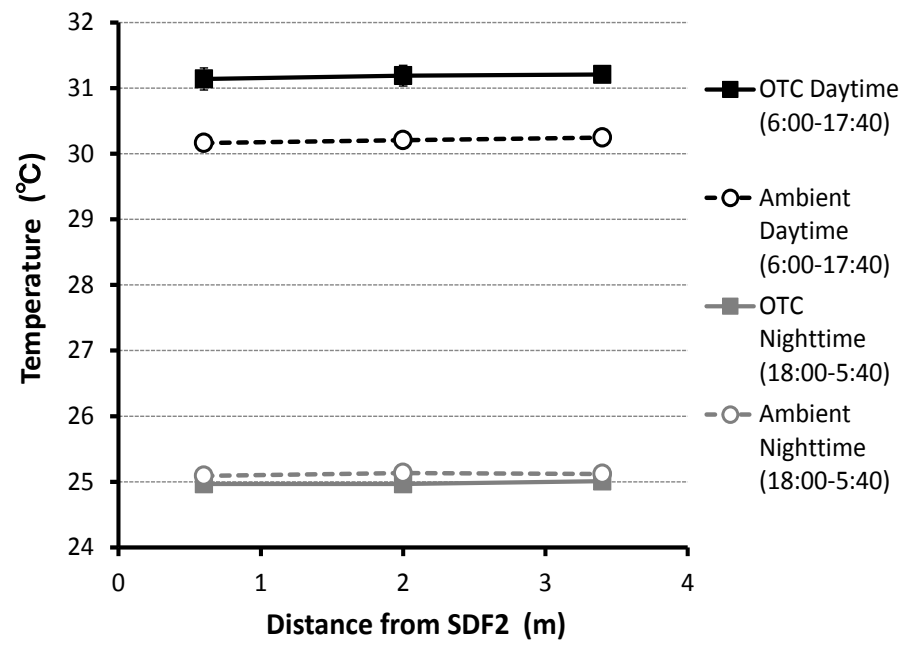

Figure 4. Ambient daytime and nighttime temperatures at different distances from the OTC-SDF2. Three wind direction scenarios were averaged. The temperatures were averaged from 4-23 August. The error bars represent the standard error among Scenarios 1 - 3. However, the bars are smaller than the symbols for all scenarios except for OTC daytime at $0.6 \mathrm{~m}$ and $2 \mathrm{~m}$.

was $27.6^{\circ} \mathrm{C}$ with maximum and minimum temperatures of $35.1^{\circ} \mathrm{C}$ and $20.3^{\circ} \mathrm{C}$, respectively, and the average relative humidity was $78 \%$. The daytime temperature inside the OTC was approximately $1^{\circ} \mathrm{C}$ higher than the temperature outside the OTC. Thus, a gradient or temperature disturbance was not observed. The nighttime temperature inside the OTC was approximately $0.13^{\circ} \mathrm{C}$ lower than the temperature outside the OTC.

Figure 5(a) shows the ambient and inside OTC temperature profile variations over a 24 hour period at different distances from the OTC-SDF2. Figure 5(b) illustrates the 
(a)

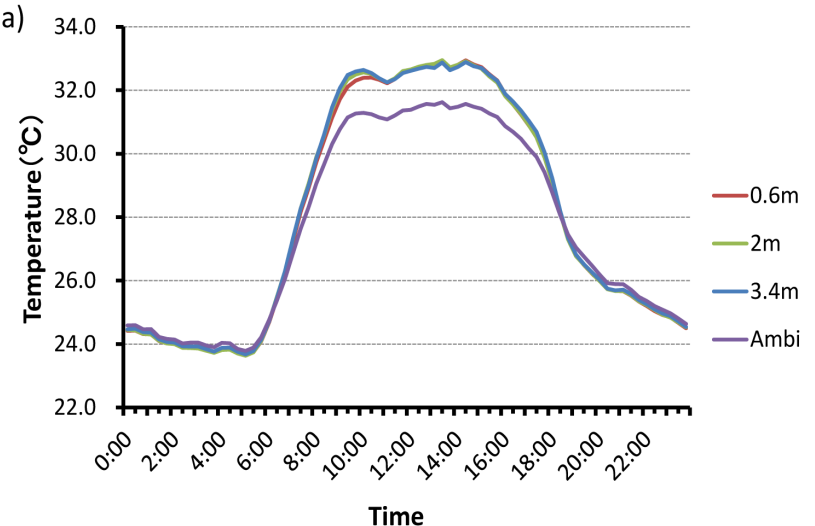

(b)

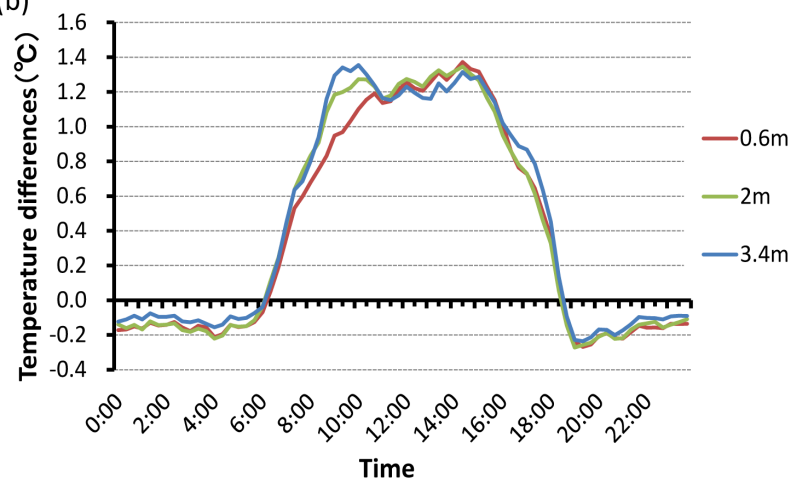

Figure 5. (a) Ambient and inside OTC temperature profile variations within a 24 hour period at different distances from the OTC-SDF2; (b) Temperature differences between the inside of the OTC and the ambient conditions. Three scenarios based on different wind directions were averaged from 4-23 August.

temperature differences between the inside of the OTC and the ambient conditions. Although the temperature difference at $0.6 \mathrm{~m}$ increased slowly before 10:00, it increased to $1.2^{\circ} \mathrm{C}-1.4^{\circ} \mathrm{C}$ from $08: 40$ to $15: 40$.

\subsection{Relationship between Solar Radiation and Temperature Increases}

We analyzed the relationships between the temperature increase inside the OTC-SDF2 and various meteorological conditions, such as the solar radiation, wind direction and wind velocity. First, we examined the relationship between the temperature increase inside the OTC-SDF2 and the integrated solar radiation for $10 \mathrm{~min}$ before the temperature measurement (Figure 6). In the figure, each point represents a daytime measurement that was taken every $20 \mathrm{~min}$ from 1-14 August using an individual data logger. In addition, linear regressions from 0.0 to $1.7 \mathrm{MJ} \cdot \mathrm{m}^{-2} \cdot \mathrm{h}^{-1}$ and from 1.9 to $3.5 \mathrm{MJ} \cdot \mathrm{m}^{-2} \cdot \mathrm{h}^{-1}$ are illustrated in Figure 6. Because numerous conditions other than solar radiation affect the measured values, each point was diversely varied and averaged. The relationship between solar radiation and temperature increases exhibited two distinct linear relationships that intersect at approximately $1.8 \mathrm{MJ} \cdot \mathrm{m}^{-2} \cdot \mathrm{h}^{-1}$. The temperature linearly increased based on the solar radiation up to approximately $1.8 \mathrm{MJ} \cdot \mathrm{m}^{-2} \cdot \mathrm{h}^{-1}$. The temperature increase then stopped and remained constant at approximately $1.4^{\circ} \mathrm{C}$ through 3.5 


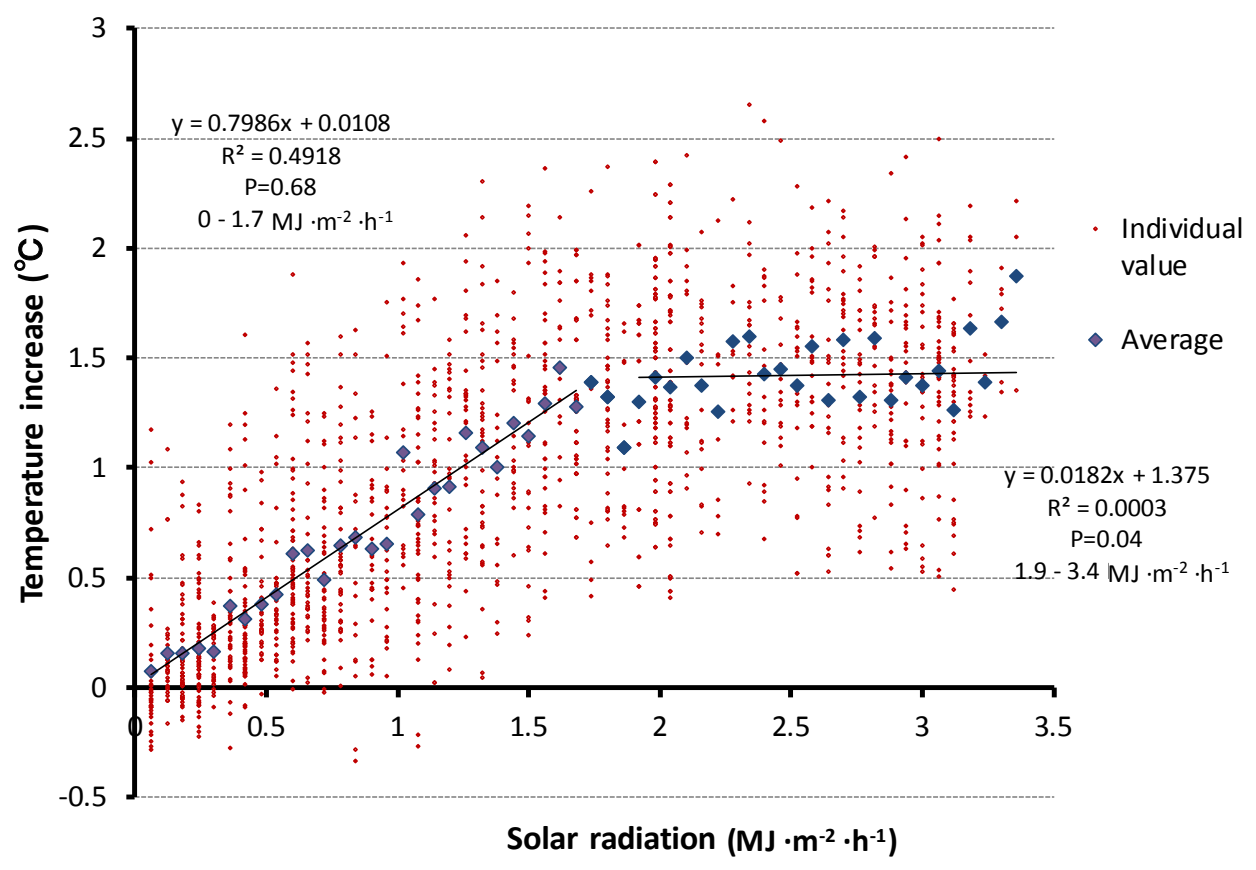

Figure 6. Relationship between solar radiation and temperature increases inside the OTC-SDF2. Linear regressions are illustrated using individual values from 0.0 to $1.7 \mathrm{MJ} \cdot \mathrm{m}^{-2} \cdot \mathrm{h}^{-1}$ and from 1.9 to $3.4 \mathrm{MJ} \cdot \mathrm{m}^{-2} \cdot \mathrm{h}^{-1}$. Each point represents a value logged by an individual data logger at $20 \mathrm{~min}$ intervals. The average solar radiation values are also displayed.

$\mathrm{MJ} \cdot \mathrm{m}^{-2} \cdot \mathrm{h}^{-1}$. Therefore, a solar radiation of $1.8 \mathrm{MJ} \cdot \mathrm{m}^{-2} \cdot \mathrm{h}^{-1}$, or more than half of full sunlight conditions, will yield a stable temperature increase in the OTC-SDF2.

\subsection{Effect of Wind Direction on Temperature Increases}

The relationship between the wind direction and OTC-SDF2 temperature increases was plotted for analysis (Figure 7). Only the values measured above $1.8 \mathrm{MJ} \cdot \mathrm{m}^{-2} \cdot \mathrm{h}^{-1}$ were used, and the average value of each deviation was added to the plot. The linear regression line illustrates that the temperature increase was slightly higher when the wind blew toward the side of the OTC-SDF2 $\left(1.4^{\circ} \mathrm{C}\right.$ parallel to the OTC-SDF2 compared with $1.5^{\circ} \mathrm{C}$ perpendicular to the OTC-SDF2). However, the difference was small, and all wind directions displayed similar effects.

\subsection{Effect of Wind Speed on Temperature Increases}

The effect of wind speed on the temperature increases based on various wind directions is shown in Figure 8. The temperature linearly decreased with increasing wind speed if the wind angle deviation was less than 22.5 degrees, with the wind passing straight through the OTC-SDF2. The relationship between the wind speed and temperature was not linear when the wind blew from the side, although an optimum wind speed-temperature relationship was exhibited. The temperature was highest for 2 to $3 \mathrm{~ms}^{-1}$ wind speeds but decreased at both lower and higher wind speeds. However, stable temperature variations were obtained for weak and strong winds in every direction. The 


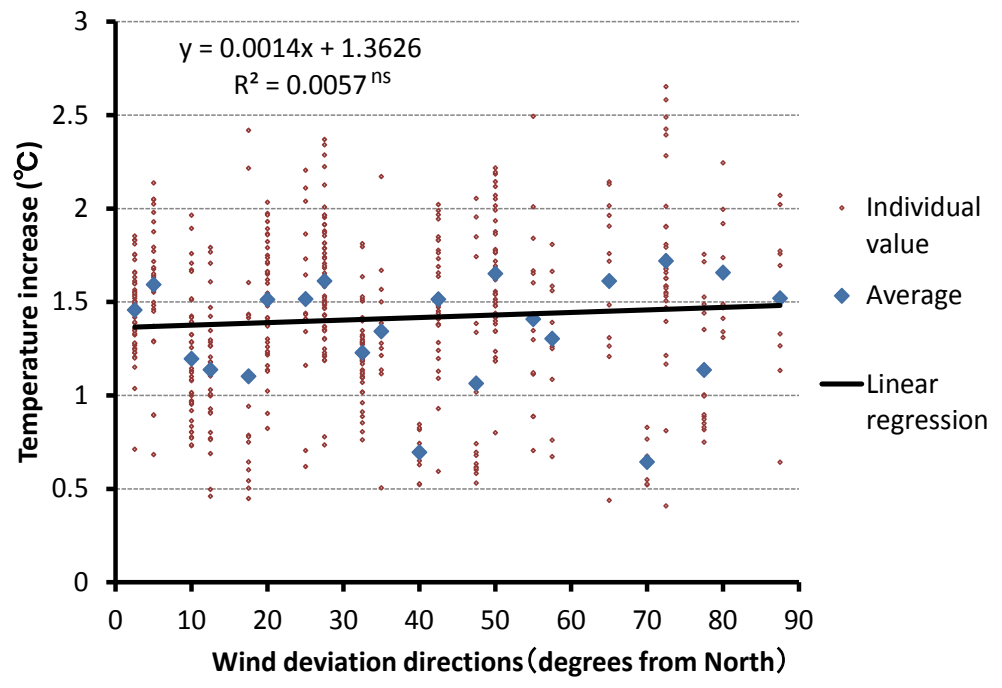

Figure 7. Relationship between the wind direction and OTC-SDF2 temperature increases for 1.8 - $3.4 \mathrm{MJ} \cdot \mathrm{m}^{-2} \cdot \mathrm{h}^{-1}$ of solar radiation. Individual and average values are illustrated, and a linear regression was added based on the individual values.
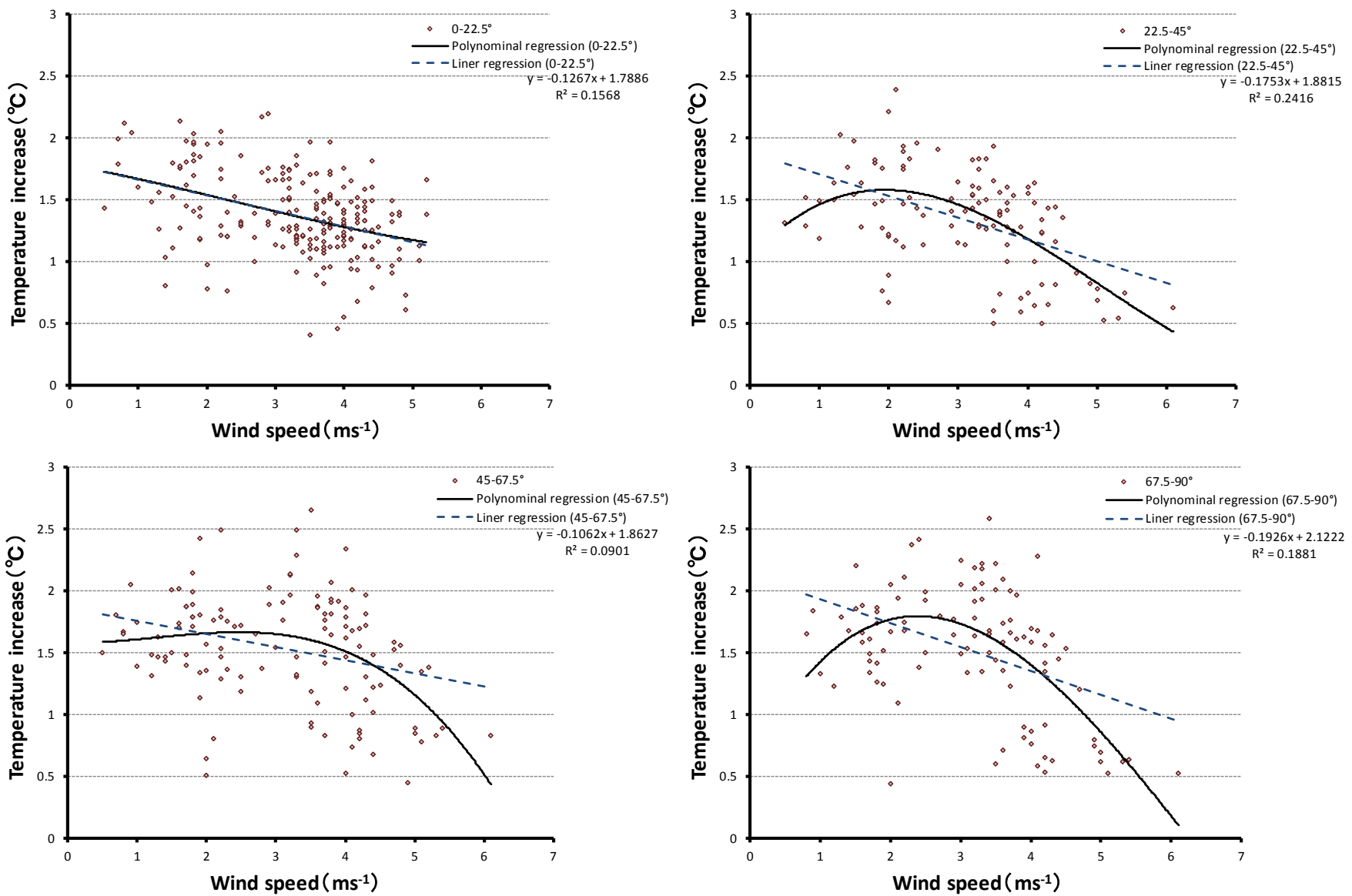

Figure 8. Effect of the wind speed on the temperature increase for various wind directions and solar radiation levels above $1.8 \mathrm{MJ} \cdot \mathrm{m}^{-2} \cdot \mathrm{h}^{-1}$. The deviation of wind direction from north is as follows: (a) 0 - 22.5 degrees; (b) 22.5 - 45 degrees; (c) 45 - 67.5 degrees; (d) 67.5 - 90 degrees. A third-order polynomial regression was added. 
temperature increase was significantly less efficient for wind speeds above $5 \mathrm{~ms}^{-1}$.

\subsection{OTC-SDF2 Performance Based on Various Wind Directions and Its Effects on Grain Quality}

The effects of the OTC-SDF2 on the grain quality of standard cultivars were evaluated based on high-temperature tolerance levels. Figure 9 shows the percentages of regular grains grown inside (high-temperature) and outside (ambient) the OTC-SDF2. This
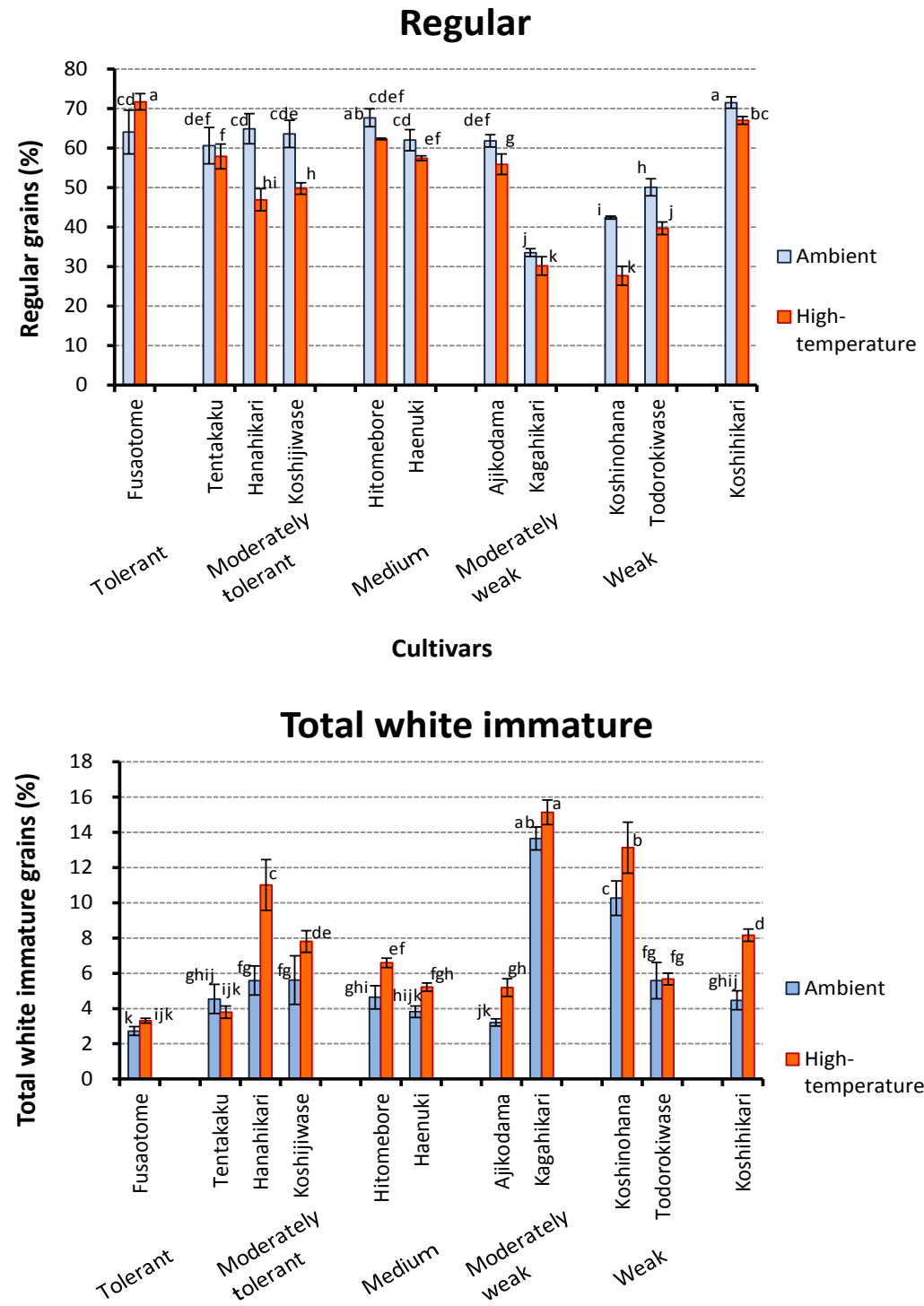

Cultivars

Figure 9. Standard cultivar grain qualities for high-temperature tolerance and Koshihikari grown using the OTC-SDF2. Percentage of regular grains (upper) and total white immature (milky white + white belly/back + basal white + dead) grains (lower) are shown. Blue and orange bars represent the ambient and high-temperature treatments. The error bars represent the standard error among Scenarios 1 to 3, which were treated as replications. Various characters close to the bars indicate significant differences as determined using a Waller-Duncan k-ratio t-test. 
experiment included three OTC-SDF2 treatment scenarios with different wind directions. All other factors were held constant. Figure 7 illustrates that the wind direction did not affect the air temperature increases inside the OTC. Therefore, directional differences may not significantly affect the temperature or the grain quality. Thus, we treated the three scenarios as replicates in the grain quality statistical analyses. The high-temperature tolerant cultivar Fusaotome exhibited a higher regular grain percentage under high-temperature conditions compared with ambient conditions. This result is related to the high cracked grain percentage observed under ambient conditions (data not shown). However, the underlying cause of the increased percentage of cracked grain is unclear. Other cultivars exhibited lower regular grain percentages under hightemperature conditions. As expected, a trend of reduced regular grain percentages was observed with more weakly rated cultivars, and this trend was more obvious under high-temperature conditions. Significant differences were not observed between the regular grain percentages of the cultivars except for in the three weakest cultivars, including Kagahikari, Koshinohana and Todorokiwase, under ambient conditions. However, a clear decreasing grain percentage trend was observed under high-temperature conditions, although Hitomebore, Haenuki and Ajikodama displayed larger than expected values.

TWI grains, which consisted of milky white, white belly/back, basal white and dead grains, displayed opposite results to that of the regular grains. This observation occurs because the regular grains are the residuals of the reduced TWIs and other problematic grains (Figure 9). Fusaotome production increased under high-temperature conditions, whereas Tentakaku production decreased. Hitomebore, Haenuki and Ajikodama exhibited high regular grain percentages, whereas Todorokiwase exhibited low grain percentages under high- temperature conditions.

\section{Discussion}

\subsection{Stable Temperature Increases in the OTC-SDF2}

Developing an easy and low-cost warming system for relatively large field areas is necessary for screening high-temperature tolerant strains during the ripening stage and evaluating crop systems under the context of high-temperature ripening and global warming. We developed the OTC-SAT [13] and OTC-SDF [17] systems, which are suitable for stable winds and low and erratic wind conditions, respectively. However, they were not suitable for moderately strong and variable direction winds. Thus, we developed the improved OTC-SDF2, which utilizes a flat tunnel between the OTC and funnels to reduce air disturbances.

As expected, the OTC-SDF2 increased the daytime average air temperature inside the OTC by approximately $1^{\circ} \mathrm{C}$ compared with the ambient conditions and regardless of the distance from the air intake. The air temperature increases were obtained under similar conditions, including the same area and similar season, as those applied for the OTC-SAT-E, which was presented in Chiba and Terao [13]. The OTC-SAT-E displayed a high temperature increase in the center of the OTC but lower temperature increases 
close to the air inlet and outlet. This OTC-SDF improved upon these uneven temperatures in slow and unstable wind conditions [17]. However, the OTC-SDF2 achieved air temperature uniformity under additional conditions, including fast and one-directional wind conditions.

The black sheet and black board that were used in the OTC-SAT and OTC-SDF were not used in the OTC-SDF2 [13] [14]; however, the use of such a material may increase the absorption efficiencies of the infrared solar radiation components. Therefore, an amount of solar energy was lost in the proposed system. Attaching a black vinyl sheet may improve the temperature increase efficiency of the OTC-SDF2.

A small difference was observed between the daily temperatures of the inlet and outlet sides of the OTC, with the morning temperature increase slightly slower on the inlet side. However, this effect was minimal (see the extent of this difference in Figure 5(a) rather than the emphasized difference in Figure 5(b)).

\subsection{Necessary Amounts of Solar Radiation}

Because the OTC-SDF2 uses solar energy to increase the air temperature inside the OTC, a stronger solar energy may be required to sufficiently increase the temperature. However, the temperature increase stabilized after the solar radiation reached more than half full sunlight conditions. This result suggests that the OTC-SDF2 can perform in non-ideal conditions.

In addition, this solar radiation plateau allows the wind speed results to be more easily analyzed because the data points obtained after the effect stabilized can be evaluated without considering the sunlight strength.

\subsection{Effect of Wind Direction}

The OTC-SDF2 was also tolerant to direction wind changes. The OTC-SDF2 equally increased the air temperature inside the OTC under winds blowing from each direction. However, the efficiency of the OTC-SDF2 slightly decreased if the wind blew straight through the apparatus. Additional results suggest that the temperature increase was slightly lower at higher wind speeds.

Surprisingly, the OTC-SDF2 was able to increase the air temperature based on perpendicular wind directions, which reduce the air flow inside the OTC-SDF2. However, side winds may cause Venturi effects, which increase air flow in the opposite side of the OTC-SDF2. Thus, the OTC-SDF2 can be adapted to all wind directions, and additional directional openings or air intakes are not necessary.

\subsection{Effect of Wind Strength Based on Various Wind Directions}

The effect of wind speed was analyzed by separating winds with different deviation angles. If the wind deviation angle is small, a higher wind speed causes the temperature to decrease, which may be caused by the ease with which the wind passes through the apparatus. Higher deviation angles require slightly stronger winds to achieve an optimal temperature increase. However, a relatively stable temperature increase was obtained 
for $1 \mathrm{~ms}^{-1}$ to $4 \mathrm{~ms}^{-1}$ wind speeds, regardless of the wind direction. Winds of more than $5 \mathrm{~ms}^{-1}$ caused the temperature increase efficiency to decrease in the OTC-SDF2. Thus, the OTC-SDF2 may not suitable for areas with continuously strong winds unless additional equipment is attached to reduce the wind speed.

\subsection{Effect on Grain Quality}

The OTC-SDF2 reduced the regular grain percentage by increasing the amount of white immature grains in most of the cultivars. The regular grain percentage was decreased in certain cultivars under high-temperature conditions, whereas it was increased in Fusaotome, which was partially because Fusaotome exhibited a significant amount of cracked grains under ambient conditions. In addition, Fusaotome and Tentakaku are high-temperature tolerant and moderately tolerant cultivars. However, the high-temperature TWI grain increase was minimal in Fusaotome and negative in Tentakaku. The OTC-SDF2 increased the temperature by approximately $1^{\circ} \mathrm{C}$ during the daytime and by approximately $1.4^{\circ} \mathrm{C}$ under more than half full sunlight conditions. This temperature increase was lower than the temperature increases observed in vinyl or green houses because warmed air can escape through the top of the OTC and prevent overheating. However, this air escape may limit the ability of the apparatus to evaluate extremely high-temperature tolerant cultivars, including cultivars stronger than Fusaotome.

\subsection{Applicability of OTC-SDF2 under Various Conditions}

The OTC-SDF2 is usable not only for screening high-temperature tolerant cultivars/ strains but also for testing cultivation methods that are applicable to resolving problems caused by high temperatures because a relatively wide range of conditions can be explored. Although we did not test the studied OTC-SDF2 at different locations and under different conditions, the tests under various wind conditions revealed that the OTC-SDF2 is applicable under various climatic conditions except for very strong winds (assuming there is sufficient solar radiation). Moreover, the necessary materials for constructing an OTC-SDF2 are not limited, suggesting that the adoption of an OTCSDF2 is possible if the availability of electricity and/or other materials is difficult, which is possible in developing countries and/or rural areas.

\section{Conclusion}

Here, we developed the OTC-SDF2, which utilized opposing entry/exit funnels connected to the OTC via flat tunnels. This device increased the average daytime temperature by approximately $1^{\circ} \mathrm{C}$ under conditions with more than half full sunlight. This equipment provided nearly identical temperature increases for each wind direction, and the temperature increases were stable for wind speeds of $1 \mathrm{~ms}^{-1}$ to $4 \mathrm{~ms}^{-1}$ in every direction. This degree of warming may be adequate for the screening of high-temperature tolerant plants from medium to weak cultivars. The OTC-SDF2 has the potential to provide moderately high-temperature treatments for screening various cultivars/strains 
and may be used to evaluate easy, low-cost cropping methods associated with hightemperature stresses.

\section{Acknowledgements}

This work was financially supported by Japan's Ministry of Agriculture, Forestry, and Fisheries (MAFF) through a research project entitled "Development of Technologies for Mitigation and Adaptation to Climate Change in Agriculture, Forestry and Fisheries". This work was partially supported by JSPS KAKENHI under grant numbers 24580030 and $15 \mathrm{~K} 07280$. We thank Dr. T. Hasegawa of the Institute for Agro-Environmental Sciences, NARO and Mr. S. Kitagawa of the Kyushu Okinawa Agricultural Research Center, NARO for coordinating with the MAFF project and Dr. T. Hirose of Hokuriku Research Station, Central Region Agricultural Research Center, NARO for his excellent technical advice. We are grateful to Mr. Tokuya Genba, Mr. Hiroyuki Nakagawa, Mr. Shinobu Yuminamochi, Mr. Koushi Yazaki, Mr. Susumu Saitou, Mr. Ken-ichi Koide, Ms. Keiko Nozaki, Ms. Setsuko Hayashi and Ms. Kiiko Takatsuto of Hokuriku Research Station for their excellent technical assistance. We also acknowledge Dr. Y. Kominami of the Hokkaido Agricultural Research Center, NARO for providing weather station data.

\section{References}

[1] Intergovernmental Panel of Climate Change (2014) Climate Change 2014, Synthesis Report, Summary for Policymakers. http://www.ipcc.ch/pdf/assessment-report/ar5/syr/AR5_SYR_FINAL_SPM.pdf

[2] Zhao, X. and Fitzgerald, M. (2013) Climate Change: Implications for the Yield of Edible Rice. PLoS One, 8, e66218. http://dx.doi.org/10.1371/journal.pone.0066218

[3] Resurreccion, A.P., Hara, T., Juliano, B.O. and Yoshida, S. (1977) Effect of Temperature during Ripening on Grain Quality of Rice. Soil Science and Plant Nutrition, 23, 109-112. http://dx.doi.org/10.1080/00380768.1977.10433027

[4] Shah, F., Huang, J., Cui, K., Nie, L., Shah, T., Chen, C. and Wang, K. (2011) Impact of High-Temperature Stress on Rice Plant and Its Traits Related to Tolerance. Journal of Agricultural Science, 149, 545-556. http://dx.doi.org/10.1017/S0021859611000360

[5] Sreenivasulu, N., Butardo Jr., V.M., Misra, G., Cuevas, R.P., Anacleto, R. and Kavi Kishor, P.B. (2015) Designing Climate-Resilient Rice with Ideal Grain Quality Suited for HighTemperature Stress. Journal of Experimental Botany, 66, 1737-1748. http://dx.doi.org/10.1093/jxb/eru544

[6] Chiba, M., Matsumura, O., Terao, T., Takahashi, Y. and Watanabe, H. (2009) Improvement of Grain Quality and Yield by Deep-Flood Irrigation. Japanese Journal of Crop Science, 78, 455-464. http://dx.doi.org/10.1626/jcs.78.455

[7] Zhu, L., Shah, F., Nie, L., Cui, K., Shah, T., Wu, W., Chen, Y., Chen, C., Wang, K., Wang, Q. and Lian, Y. (2013) Efficacy of Sowing Date Adjustment as a Management Strategy to Cope with Rice (Oryza sativa L.) Seed Quality Deterioration Because of Elevated Temperature. Australian Journal of Crop Science, 7, 543-549.

[8] Horie, T., Nakagawa, H., Nakano, J., Hamotani, K. and Kim, H.Y. (1995) Temperature Gradient Chambers for Research on Global Environment Change. III. A System Designed 
for Rice in Kyoto, Japan. Plant Cell and Environment, 18, 1064-1069.

http://dx.doi.org/10.1111/j.1365-3040.1995.tb00618.x

[9] Ishizaki, K. (2006) Evaluation of Various Screening Systems for High Grain Quality in Rice Culti-Vars under High-Temperature Grain-Filling Conditions, and the Selection of Their Standard Cultivars. Japanese Journal of Crop Science, 75, 502-506. http://dx.doi.org/10.1626/jcs.75.502

[10] Kimball, B.A., Conley, M.M., Wang, S., Lin, X., Luo, C., Morgan, J. and Smith, D. (2008) Infra-Red Heater Arrays for Warming Ecosystem Field Plots. Global Change Biology, 14, 309-320. http://dx.doi.org/10.1111/j.1365-2486.2007.01486.x

[11] Komaki, Y., Sasahara, H. and Uehara, Y. (2002) Varietal Differences of Ripening Ability Among Early-Maturing Rice Varieties under High Temperature in a Vinyl House. Hokuriku Crop Science, 37, 12-16.

[12] Terao, T., Chiba, M. and Hirose, T. (2010) A Simple Equipment to Screen the Rice Strains Tolerant to High Temperature in the Ripening Processes. Japanese Journal of Crop Science, 79, 166-173. http://dx.doi.org/10.1626/jcs.79.166

[13] Chiba, M. and Terao, T. (2014) Open-Top Chambers with Solar-Heated Air Introduction Tunnels for the High-Temperature Treatment of Paddy Fields. Plant Production Science, 17, 152-165. http://dx.doi.org/10.1626/pps.17.152

[14] Heagle, A.S., Body, D.E. and Heck, W.W. (1973) An Open-Top Field Chamber to Assess the Impact of Air Pollution on Plants. Journal of Environmental Quality, 2, 365-368. http://dx.doi.org/10.2134/jeq1973.00472425000200030014x

[15] Rogers, H.H., Heck, W.W. and Heagle, A.S. (1983) A Field Technique for the Study of Plant Responses to Elevated Carbon Dioxide Concentrations. Journal of the Air Pollution Control Association, 33, 42-44. http://dx.doi.org/10.1080/00022470.1983.10465546

[16] Norby, R., Edwards, N., Riggs, J., Abner, C., Wullschleger, S. and Gunderson, C. (1997) Temperature-Controlled Open-Top Chambers for Global Change Research. Global Change Biology, 3, 259-267. http://dx.doi.org/10.1046/j.1365-2486.1997.00072.x

[17] Chiba, M. and Terao, T. (2015) Improvement of High-Temperature Treatments Using Solar Radiation for Heat Tolerance Screening under Unstable Wind Condition. Plant Production Science, 18, 414-420. http://dx.doi.org/10.1626/pps.18.414

[18] Yokoyama, K., Ohno, H., Kominami, Y., Inoue, S. and Kawakata, T. (2003) Performance of Japanese Precipitation Gauges in Winter. Seppyo, 65, 303-316. http://dx.doi.org/10.5331/seppyo.65.303 
Submit or recommend next manuscript to SCIRP and we will provide best service for you:

Accepting pre-submission inquiries through Email, Facebook, LinkedIn, Twitter, etc. A wide selection of journals (inclusive of 9 subjects, more than 200 journals)

Providing 24-hour high-quality service

User-friendly online submission system

Fair and swift peer-review system

Efficient typesetting and proofreading procedure

Display of the result of downloads and visits, as well as the number of cited articles

Maximum dissemination of your research work

Submit your manuscript at: http://papersubmission.scirp.org/

Or contact as@scirp.org 